\title{
Analysis of genomic aberrations associated with the clinicopathological parameters of rectal cancer by array-based comparative genomic hybridization
}

\author{
JIAN-WEI LIANG $^{1 *}$, ZHI-ZHOU SHI ${ }^{2 *}$, TONG-TONG ZHANG ${ }^{2}$, JIA-JIE HAO ${ }^{2}$, ZHENG WANG $^{1}$, \\ XIAO-MIN WANG ${ }^{2}$, HAI YANG ${ }^{2}$, MING-RONG WANG $^{2}$, ZHI-XIANG ZHOU $^{1}$ and YU ZHANG ${ }^{2}$ \\ ${ }^{1}$ Department of Abdominal Surgical Oncology, ${ }^{2}$ State Key Laboratory of Molecular Oncology, Cancer Hospital and Institute, \\ Chinese Academy of Medical Sciences and Peking Union Medical College, Beijing, P.R. China
}

Received December 11, 2012; Accepted January 28, 2013

DOI: 10.3892/or.2013.2296

\begin{abstract}
The aim of the present study was to screen and identify the chromosomal aberrations that are correlated with clinicopathological characteristics of rectal cancer using array-based comparative genomic hybridization (array-CGH). Forty-eight fresh frozen tumor tissues of rectal carcinoma were analyzed by array-CGH. The results showed that most frequent gains included 8q24.3, 20q11.21-q13.32,20q13.33 and losses in 8p23.3-p12, 17p13.1-p12 and 18q11.2-q23 were noted. Fourteen amplifications and seven homozygous deletions were identified in the rectal cancer samples. Losses of 4p16.1-p15.31, 8p21.1-p12 and gains of 7p12.3-p12.1 and 13q33.1-q34 were associated with positive lymph node status and advanced clinical stage (stages III and IV). The 17q24.2-25.3 gain was more frequent in patients with distant metastasis. Integrated analysis indicated that overexpression of PDP1, TRIB1, C13orf27, FOXA2, PMEPA1 and PHACTR3 was associated with gains, and underexpression of FHOD, SMAD4 and BCL2 was associated with losses. Pathway enrichment analysis showed that pathways of nitrogen metabolism, oxidative phosphorylation, cell cycle, maturity onset diabetes of young, cytokine-cytokine receptor interaction, MAPK signaling pathway and dentatorubropallidoluysian atrophy were influenced by copy number changes.
\end{abstract}

Correspondence to: Dr Yu Zhang, State Key Laboratory of Molecular Oncology, Cancer Hospital and Institute, Chinese Academy of Medical Sciences and Peking Union Medical College, 17 Panjiayuannanli, P.O. Box 2258, Chaoyang, Beijing 100021, P.R. China

E-mail: zhangyu909@126.com

Dr Zhi-Xiang Zhou, Department of Abdominal Surgical Oncology, Cancer Hospital and Institute, Chinese Academy of Medical Sciences and Peking Union Medical College, 17 Panjiayuannanli, Chaoyang, Beijing 100021, P.R. China

E-mail: zhouzx01@yahoo.com.cn

*Contributed equally

Key words: genomic aberration, clinicopathological parameter, rectal cancer, array-based comparative genomic hybridization

\section{Introduction}

Colorectal cancer (CRC) is a common malignant tumor worldwide, and over 1.2 million new cases and 608,700 deaths were estimated to have occurred in 2008 (1). The incidence of CRC in China has increased rapidly since the 1980s (2,3). Currently, $\mathrm{CRC}$ is the fifth leading cause of cancer-related deaths (4).

CRC can be divided into two types based on genetic abnormalities $(5,6)$. The major type is the chromosomal instability phenotype, which consists of more than $85 \%$ of CRCs and is characterized by frequent chromosomal imbalances. The minor type is the microsatellite instability phenotype, which exhibits microsatellite instability owing to DNA replication errors and comprises $<15 \%$ of CRCs. The genomic instability of the two types can lead to DNA copy number aberrations.

Cancers occur as a result of the accumulation of genetic alterations that are associated with carcinogenesis $(5,7)$. Thus, the study of the cancer genome by high-resolution and highthroughput technology, for example array-based comparative genomic hybridization (array-CGH), not only has the ability to clarify the relationship between genomic abnormalities and clinicopathological factors, but may also optimize the treatment of patients by using their cancer genome information. Although several DNA copy number aberrations have been reported to have linkage with clinicopathological characteristics of patients with CRC (8-10), the available information is still limited particularly in Chinese patients.

The present study identified frequent DNA copy number changes in rectal cancer samples from Chinese patients and candidate target genes using integrated analysis of the genome and gene expression data of NCI-60 cell lines. We evaluated the genetic changes associated with lymph node metastasis, tumor stage and distant metastasis using the methods of frequency plot comparison together with statistical analysis.

\section{Materials and methods}

Study design. This study was conducted to identify genomic changes associated with clinicopathological factors and candidate targets of most frequent gains and losses of rectal cancer. We determined the genetic aberrations in 48 rectal carcinomas 
using Agilent 60K Human Genome CGH microarray and screened those linked with clinicopathological characteristics. We then compared the gene expression profiling of CRC cell lines with or without gains of 8q, 13q, 17q, 20p, 20q or losses of $8 p, 11 q, 18 q$ and identified genes whose expression was linked with DNA copy number changes.

Patients and samples. Fresh tissues from 48 rectal carcinoma patients were collected at the Department of Pathology, Cancer Hospital, Peking Union Medical College and Chinese Academy of Medical Sciences, Beijing, China. None of the patients received either irradiation or chemotherapy prior to surgery. All of the samples used in this study were residual specimens after diagnostic sampling. Every patient signed a separate informed consent form for sampling and research. Ethics approval was obtained from the Ethics Committee of Cancer Institute and Hospital, Chinese Academy of Medical Sciences. Representative tumor regions were excised by experienced pathologists. The clinicopathologic characteristics of the patients are summarized in Table I.

Genomic DNA extraction. Genomic DNA was isolated from tumor tissues using the Qiagen DNeasy Blood and Tissue kit as described by the manufacturer (Qiagen, Hilden, Germany). Tumor cell content of all the samples was $>50 \%$ as determined by H\&E staining.

Array-based CGH. Array-CGH experiments were performed using standard Agilent protocols (Agilent Technologies, Santa Clara, CA, USA). Commercial human genomic DNA (Promega, Warrington, UK) was used as reference. For each CGH hybridization, $400 \mathrm{ng}$ of reference genomic DNA and the same amount of tumor DNA were digested with $A l u \mathrm{I}$ and RSAI restriction enzymes (Promega). The digested reference DNA fragments were labeled with cyanine 3-dUTP and the tumor DNA with cyanine 5-dUTP (Agilent Technologies). After clean-up, reference and tumor DNA probes were mixed and hybridized onto an Agilent 60K human genome CGH microarray (Agilent Technologies) for $24 \mathrm{~h}$. Washing, scanning and data extraction procedures were performed following standard protocols.

Microarray data analysis. Microarray data were analyzed using Agilent Genomic Workbench (Agilent Technologies), CGH ArrayTools (http://linus.nci.nih.gov/BRB-ArrayTools. $\mathrm{html}$ ) and MD-SeeGH (www.flintbox.ca). Agilent Genomic Workbench was used to calculate the $\log 2$ ratio for every probe and identified genomic aberrations. Mean Log2ratio of all probes in a chromosome region between 0.25 and 0.75 was classified as a genomic gain, $>0.75$ as high-level DNA amplification, $<-0.25$ as a hemizygous loss, and $<-0.75$ as a homozygous deletion. Pathway enrichment analyses were performed by CGH ArrayTools.

Integration analysis of DNA copy number and gene expression data of the NCI 60 cell lines. The DNA copy number and gene expression data of the NCI 60 cell lines were obtained from CellMiner (http://discover.nci.nih.gov/cellminer). We selected the data sets of aCGH Agilent $44 \mathrm{~K}$ and Agilent mRNA for analysis. The genetic changes of seven CRC cell lines (including colo205, HCT_116, HCT_15, KM12, HCC_2998,
Table I. Clinicopathological characteristics of the rectal cancer patients in the array-CGH study.

\begin{tabular}{|c|c|c|c|c|}
\hline Patient no. & Gender & Age (years) & TNM & pStage \\
\hline 1 & M & 67 & T3N1M0 & III B \\
\hline 2 & M & 58 & $\mathrm{~T} 3 \mathrm{~N} 1 \mathrm{M} 0$ & III B \\
\hline 3 & M & 43 & T4N2M1 & III C \\
\hline 4 & F & 63 & T3N2M0 & III C \\
\hline 5 & $\mathrm{~F}$ & 69 & T4N2M0 & III C \\
\hline 6 & F & 52 & $\mathrm{~T} 3 \mathrm{~N} 2 \mathrm{M} 0$ & III C \\
\hline 7 & M & 56 & T3N2M1 & III C \\
\hline 8 & F & 47 & T4N2M0 & III C \\
\hline 9 & $\mathrm{~F}$ & 61 & T4N2M0 & III C \\
\hline 10 & M & 41 & T3N2M1 & III C \\
\hline 11 & M & 58 & $\mathrm{~T} 3 \mathrm{~N} 2 \mathrm{M} 1$ & IV \\
\hline 12 & $\mathrm{~F}$ & 62 & T3N1M1 & IV \\
\hline 13 & $\mathrm{~F}$ & 36 & T3N0M1 & IV \\
\hline 14 & M & 59 & T3N0M1 & IV \\
\hline 15 & M & 49 & T3N1M1 & IV \\
\hline 16 & M & 53 & $\mathrm{~T} 3 \mathrm{~N} 2 \mathrm{M} 1$ & IV \\
\hline 17 & M & 75 & T3N2M1 & IV \\
\hline 18 & F & 79 & $\mathrm{~T} 3 \mathrm{~N} 2 \mathrm{M} 0$ & III C \\
\hline 19 & $\mathrm{~F}$ & 22 & $\mathrm{~T} 4 \mathrm{~N} 2 \mathrm{M} 0$ & III C \\
\hline 20 & $\mathrm{~F}$ & 70 & $\mathrm{~T} 4 \mathrm{~N} 2 \mathrm{M} 0$ & III C \\
\hline 21 & M & 77 & $\mathrm{~T} 4 \mathrm{~N} 2 \mathrm{M} 0$ & III C \\
\hline 22 & M & 36 & $\mathrm{~T} 3 \mathrm{~N} 1 \mathrm{M} 0$ & III B \\
\hline 23 & M & 49 & T3N0M0 & II A \\
\hline 24 & M & 45 & T4N0M0 & II B \\
\hline 25 & M & 61 & T3N0M0 & II A \\
\hline 26 & $\mathrm{M}$ & 51 & T3N0M0 & II A \\
\hline 27 & $\mathrm{~F}$ & 66 & T3N0M1 & II A \\
\hline 28 & M & 59 & T3N0M1 & II A \\
\hline 29 & $\mathrm{M}$ & 45 & T3N0M0 & II A \\
\hline 30 & M & 72 & T3N0M0 & II A \\
\hline 31 & M & 63 & T3N0M0 & II A \\
\hline 32 & M & 58 & T3N0M0 & II A \\
\hline 33 & M & 68 & T3N0M0 & II A \\
\hline 34 & M & 63 & T3N0M0 & II A \\
\hline 35 & M & 63 & T3N0M0 & II A \\
\hline 36 & M & 55 & T3N0M0 & II A \\
\hline 37 & M & 42 & T3N0M0 & II A \\
\hline 38 & $\mathrm{~F}$ & 56 & T3N0M0 & II A \\
\hline 39 & F & 52 & T4N0M0 & II B \\
\hline 40 & M & 45 & T4N0M0 & II B \\
\hline 41 & M & 47 & T4N0M0 & II B \\
\hline 42 & M & 62 & T4N0M0 & II B \\
\hline 43 & M & 64 & T3N1M0 & III B \\
\hline 44 & F & 53 & T4N1M0 & III B \\
\hline 45 & F & 59 & T3N1M0 & III B \\
\hline 46 & $\mathrm{~F}$ & 49 & $\mathrm{~T} 3 \mathrm{~N} 1 \mathrm{M} 0$ & III B \\
\hline 47 & $\mathrm{~F}$ & 39 & $\mathrm{~T} 3 \mathrm{~N} 1 \mathrm{M} 0$ & III B \\
\hline 48 & $\mathrm{M}$ & 63 & T3N1M1 & III B \\
\hline
\end{tabular}



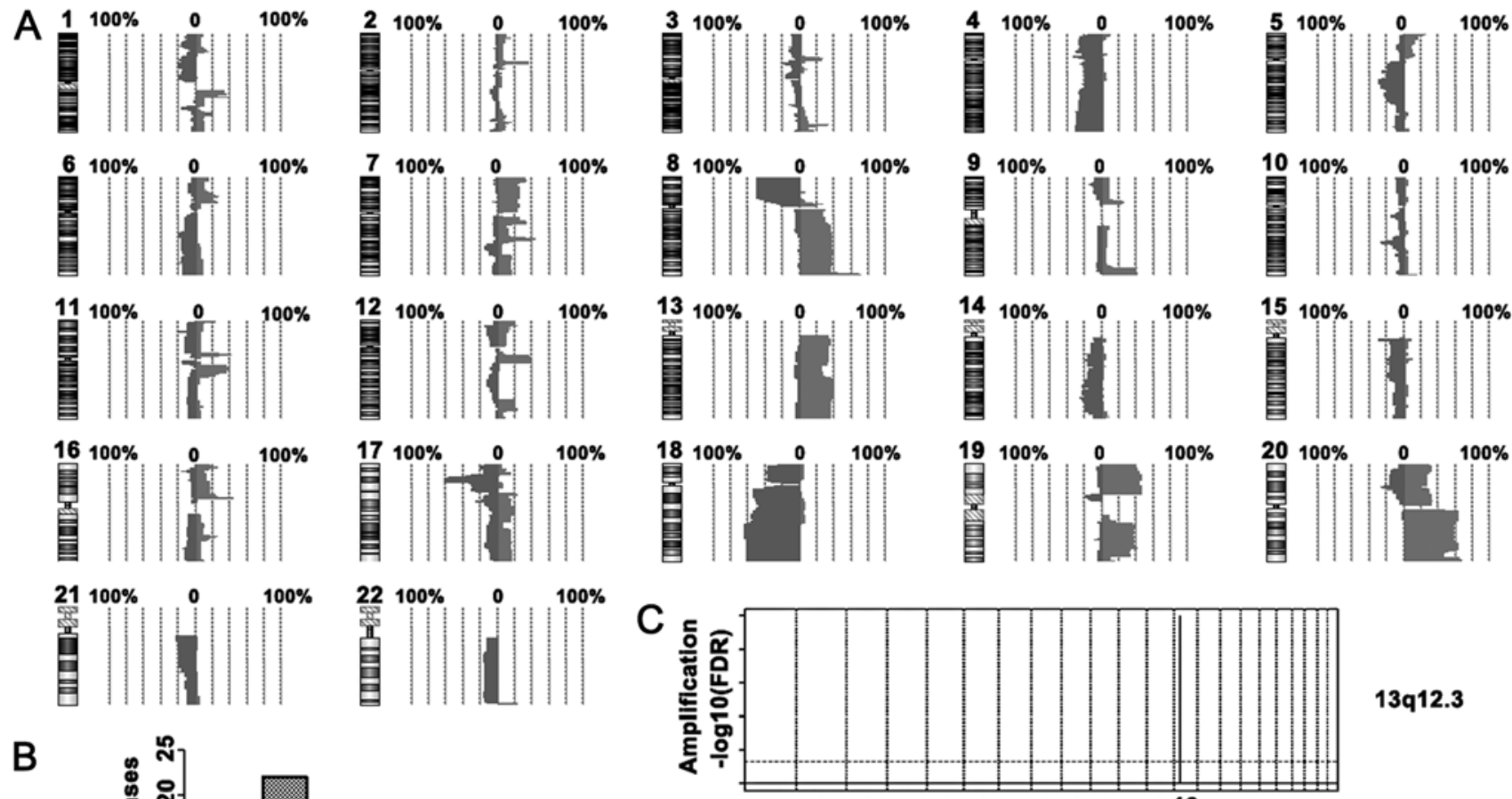

$13 q 12.3$

B
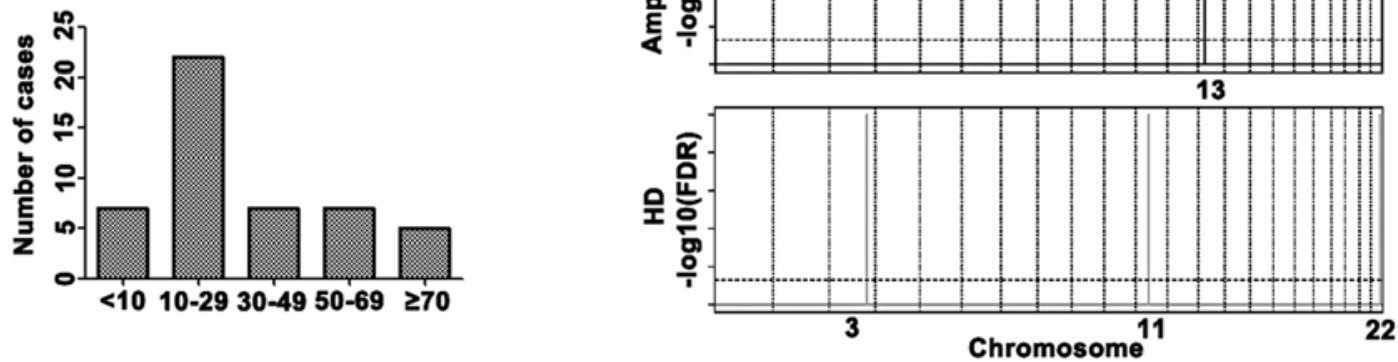

3q26.1

$11 q 11$

22q13.2

Figure 1. Genomic profiling of rectal cancer in the array-CGH assay. (A) Frequency plot of rectal cancer. Right of 0-axis, gains; left of 0-axis, losses. (B) Number of genomic aberrations; $x$-axis, number of aberrations; $y$-axis, number of cases. (C) Amplification and homozygous deletions identified by GISTIC analysis.

HT29 and SW_620) were analyzed and divided into the gain/ loss group and no change group. The differentially expressed genes between the two groups were indentified with a cutoff of a 2-fold change using GeneSpring GX (Agilent Technologies).

Oncomine data analysis. The mRNA expression of genes which had a $>5$-fold change in expression between the gain/loss CRC cell lines and the no change cell lines was analyzed using Oncomine database (https://www.oncomine.org/resource/ login.html). Details of standardized normalization techniques and statistical methods can be found on the the Oncomine website. The data of the interested genes in different types of cancer were collected and then their expression status in CRC was analyzed.

Statistical analysis. The Chi-square test was used to analyze the significance of correlation between genomic aberrations and clinical factors. Differences were considered significant at $\mathrm{P}<0.05$.

\section{Results}

Recurrent copy number alterations in rectal carcinoma detected by array-CGH. Forty eight samples of rectal carcinoma were analyzed in this study and all of them had genomic changes. The most frequent genomic aberrations were gains of 8q24.3, 20q11.21-q13.32, 20q13.33, and losses of 8p23.3-p12, 17p13.1-p12 and 18q11.2-q23 (Fig. 1A). High-level amplifications were detected at 14 chromosome regions including 7p22.3-p21.3, 7q22.1, 8p11.21, 8p11.23, 8q22.1, 8q24.3, 13q12.2, 13q14.2-q14.3, 13q31.3, 16p11.2, 19p13.2, 20p11.23, 20q11.21-q11.23 and 20q13.33. Homozygous deletions were identified in 5q14.3, 8p23.3-p21.2, 15q11.2, 16p13.2, 17p13.1p12, 18q21.2 and 20p12.1 (Table II). After analyzing the number of changes in rectal cancer, we found that nearly half of cases in the array-CGH study had 10 to 29 genetic alterations (Fig. 1B). GISTIC analysis showed that a copy number increase of MTUS2 (13q12.3) and decrease of C3orf57 (3q26.1), SPRYD5 (11q11), OR5W2 (11q11) and MKL1 (22q13.2) were significant in the rectal cancer cases (Fig. 1C).

Genomic changes associated with lymph node metastasis, tumor stage and distant metastasis. We compared the frequencies of genomic aberrations in the rectal cancer patients subdivided accoding to cases with or without lymph node metastasis, with tumor stages II or III-IV, and with or without distant metastasis using MD-SeeGH software. The results showed that gains of $7 p, 13 q$ and losses of $4 p, 4 q$ and $8 \mathrm{p}$ were more frequent in the rectal cancers with lymph node metastasis (Fig. 2A). The frequencies of 7p, 13q gain and $4 \mathrm{q}$ loss were higher in stage III-IV cases when compared with the frequencies in stage II cases (Fig. 2B). The largest differences were detected in copy number changes of $4 \mathrm{q}$ and $17 \mathrm{q}$, with more frequent $4 \mathrm{q}$ loss and $17 \mathrm{q}$ gain in the cases with distant 
Table II. High-level amplifications and homozygous deletions in the rectal cancer cases.

\begin{tabular}{|c|c|c|c|c|c|c|}
\hline Changes & Cytoband & Start & End & No. of probes & No. of cases & Candidates \\
\hline \multirow[t]{14}{*}{ Amp } & $7 q 22.1$ & 99852752 & 100767476 & 42 & 5 & MUC17 \\
\hline & $7 \mathrm{p} 22.3-\mathrm{p} 21.3$ & 524935 & 7428910 & 128 & 3 & FSCN1 \\
\hline & $8 \mathrm{q} 24.3$ & 145210837 & 145782038 & 24 & 11 & FOXH1 \\
\hline & $8 q 22.1$ & 95061529 & 97342088 & 45 & 4 & CDH17 \\
\hline & $8 p 11.23$ & 39378051 & 39461834 & 3 & 8 & ADAM5P, ADAM3A \\
\hline & $8 p 11.21$ & 42816942 & 42849186 & 3 & 4 & THAP1, RNF170 \\
\hline & $13 q 12.2$ & 27095352 & 27439560 & 11 & 4 & CDX2 \\
\hline & $13 q 14.2-q 14.3$ & 46790942 & 51899157 & 117 & 4 & ALG11 \\
\hline & $13 q 31.3$ & 91075476 & 91176960 & 4 & 4 & GPC5 \\
\hline & $16 \mathrm{p} 11.2$ & 29890929 & 31412127 & 78 & 4 & MAPK3 \\
\hline & $19 \mathrm{p} 13.2$ & 11141557 & 11548932 & 29 & 3 & CNN1 \\
\hline & 20q11.21-q11.23 & 29501535 & 35014201 & 155 & 10 & \\
\hline & $20 q 13.33$ & 60008660 & 62320720 & 85 & 6 & PTK6, TNFRSF6B \\
\hline & 20 p11.23 & 18692429 & 20864752 & 42 & 3 & \\
\hline \multirow[t]{8}{*}{ HD } & $5 q 14.3$ & 87722621 & 90788169 & 48 & 3 & MEF2C \\
\hline & $8 \mathrm{p} 23.3-\mathrm{p} 21.2$ & 211611 & 27199611 & 467 & 3 & DLC1, PCM1 \\
\hline & $15 q 11.2$ & 18835660 & 20010618 & 12 & 5 & \\
\hline & $16 \mathrm{p} 13.2$ & 6492886 & 6860972 & 9 & 3 & A2BP1 \\
\hline & 17p13.1-p12 & 11089880 & 15073870 & 69 & 3 & MAP2K4 \\
\hline & $18 \mathrm{q} 21.2$ & 46764796 & 47107764 & 9 & 3 & SMAD4 \\
\hline & $18 \mathrm{q} 21.2$ & 48023000 & 48423627 & 8 & 3 & $\mathrm{DCC}$ \\
\hline & 20p12.1 & 14772372 & 14939552 & 4 & 4 & MACROD2 \\
\hline
\end{tabular}

metastasis (Fig. 2C). We analyzed these candidate genomic regions with clinical factors by Chi-square test, and found that losses of 4p16.1-p15.31, 8p21.1-p12 and gains of 7p12.3-p12.1 and 13q33.1-q34 were associated with positive lymph node metastasis and advanced clinical stage (stages III and IV). Moreover, loss of 4q34.3-q35.1 was linked only with advanced stage (stages III and IV). We also found that the patients with distant metastasis had more frequent 17q24.2-25.3 gain (Table III).

Candidate target genes of gains and losses in rectal carcinoma. We performed an integrated analysis of the array-CGH dataset and the gene expression profiling dataset of CRC cells of NCI-60 to identify the candidate target genes of genomic gains and losses. The expression level of CA2, PDP1, ANGPT1, LOC346887, MAL2, NOV, TRIB1 and ZNF572 was higher in cell lines with an $8 \mathrm{q}$ gain than without. We also analyzed candidate target genes of gains in 13q, 17q, 20p and $20 q$ and of loss in 18q (Table IV) and found that PDP1 (8q), TRIB1 (8q), C13orf27 (13q), FOXA2 (20p), PMEPA1 (20q) and PHACTR3 (20q) were overexpressed not only in CRC but also in other types of cancers (Table V). Three genes in $18 \mathrm{q}$ (FHOD, SMAD4 and BCL2) presented underexpression in several types of cancers including CRC (Table V).

Pathways enriched for copy number alterations. Pathway enrichment analysis using KEGG database was applied to the CGH data, and we found four pathways enriched in genes with gain and three pathways enriched in genes with loss. The genomic gains in rectal carcinoma changed the pathways of nitrogen metabolism, oxidative phosphorylation, cell cycle and maturity onset diabetes of young. However, cytokine-cytokine receptor interaction, MAPK signaling pathway, and dentatorubropallidoluysian atrophy (DRPLA) pathways were changed by the genomic losses (Table VI).

\section{Discussion}

The biological properties of cancers are different in patients presenting with different clinical parameters such as invasive depth, lymph node metastasis, distant metastasis, differentiation and clinical stage. Thus, the optimal treatment should be based on an individual cancer. Biomarkers can improve the accuracy of determining the clinical parameters that are predictors of prognosis and indicators of a response to treatment.

By applying array-CGH to rectal carcinoma samples of Chinese parients, we screened the genomic aberrations associated with clinical parameters using frequency comparison. The results showed that losses of 4p16.1-p15.31, 8p21.1-p12 and gains of 7p12.3-p12.1 and 13q33.1-q34 were associated with positive lymph node metastasis and advanced clinical stage (stages III and IV). Loss of 4q34.3-q35.1 was a marker of advanced stage (stages III and IV). We also found that the patients with distant metastasis had a more frequent gain in 17q24.2-25.3. Chromosome 4 was found to be the most frequent loss region in cancers including cervical, esophageal, lung, head and neck, gastric and CRC (11-16). The incidence of 4q loss was much higher in pulmonary metastatic tissues when compared 
A
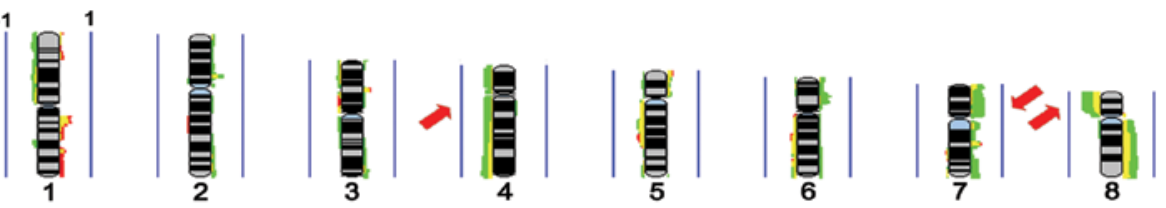

pNO
VS
pN1
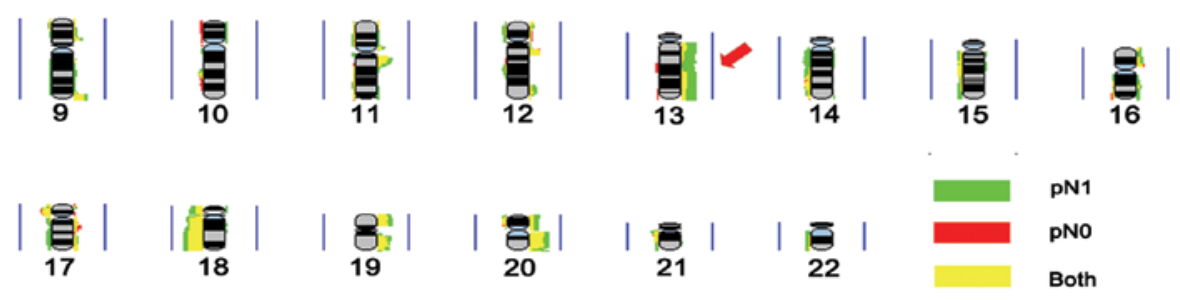

B
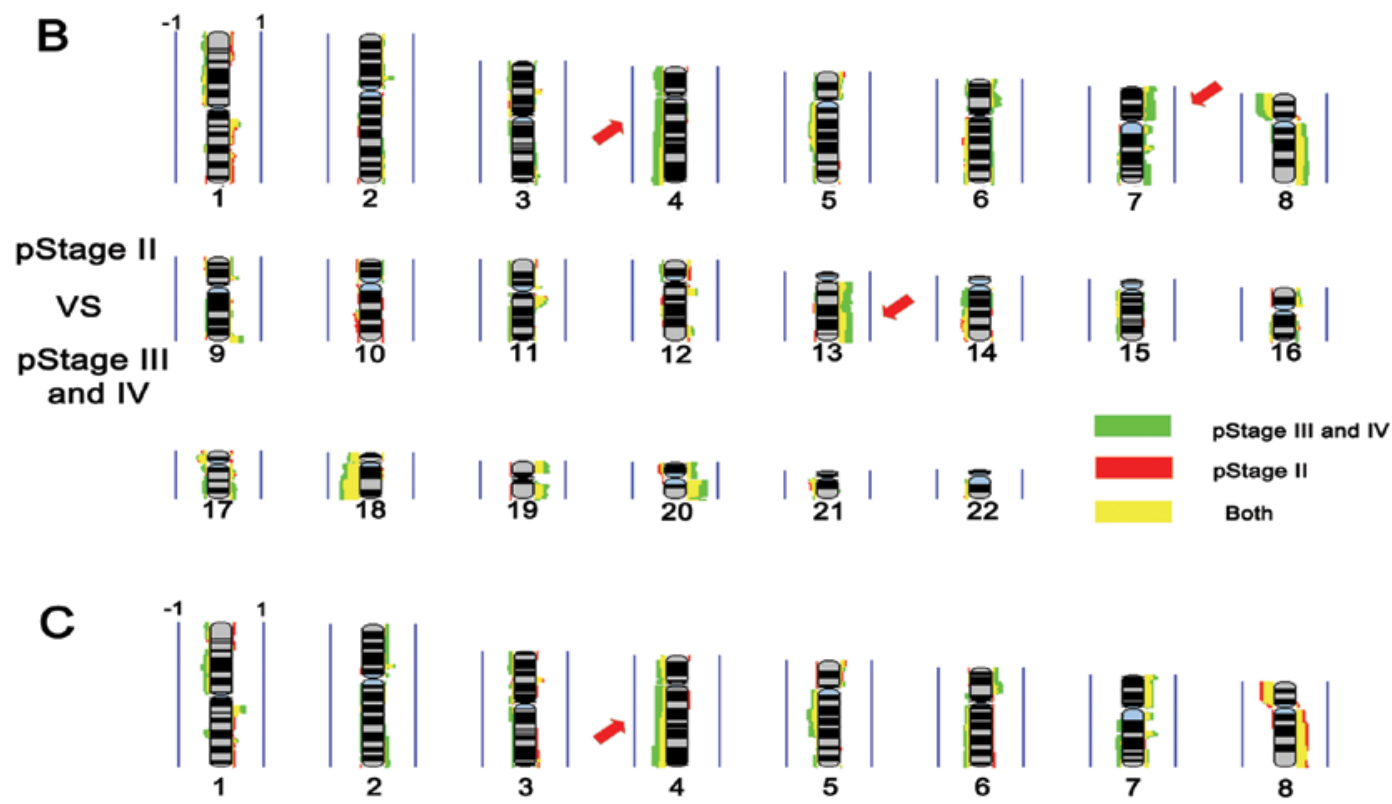

pMo
vs
pM1
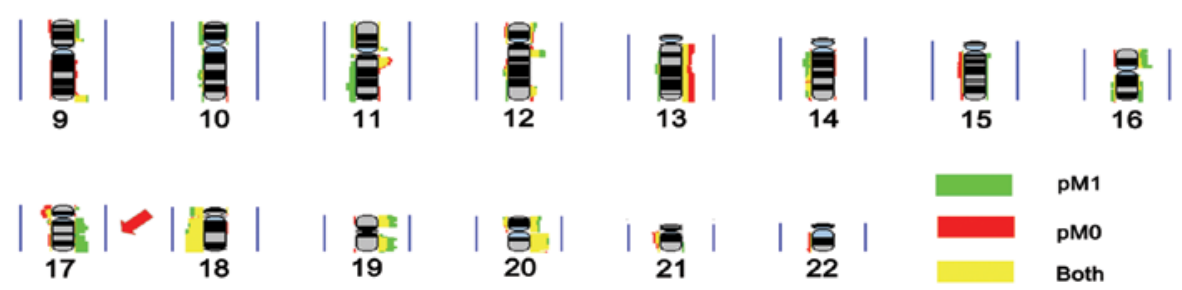

Figure 2. Frequency plot comparison. (A) Frequency plot comparison between pN1 and pN0. Red, pN0 group; green, pN1 group; yellow, shared by two groups. (B) Frequency plot comparison between pStage II and pStage III-IV. Red, pStage II group; green, pStage III-IV group; yellow, shared by two groups. (C) Frequency plot comparison between pM1 and pM0. Red, pM0 group; green, pM1 group; yellow, shared by two groups. The presentation is per array probe; gains are represented by the colors on the right, and losses are represented by the colors on the left. Vertical blue line represents $100 \%$ of the samples. Red arrows highlight the chromosomal areas with different frequency in two groups.

with primary cancer tissues and LOH of the D4S1534 locus (4q) in primary tissues was significantly linked with liver metastasis $(17,18)$. Our results also suggested that loss of $4 \mathrm{q}$ in primary rectal tissues was a candidate predictor of lymph node metastasis. This indicates that target genes of the loss of $4 \mathrm{q}$ play important roles in lymphatic invasion and tumor progression, to which further investigation should be addressed.

The correlation of $17 \mathrm{q}$ with clinicopathological factors of CRC was not explicit. Diep et al (7) found that gain of $17 \mathrm{q}$ was correlated with the transition from a primary tumor to liver metastasis, while Knosel et al (16) reported that more deletion at $17 \mathrm{q}$ were observed in lung metastasis than primary tumors (19). Our results showed that the gain of $17 q$ was more frequent in rectal cancer patients with distant metastasis when compared with patients without metastasis. Additional independent validation assays should be performed to reveal the correlation of $17 \mathrm{q}$ and metastasis.

Our results revealed that the alteration in expression of PDP1 (8q), TRIB1 (8q), C13orf27 (13q), FOXA2 (20p), PMEPA1 (20q), PHACTR3 (20q), FHOD (18q), SMAD4 (18q) and BCL2 (18q) occurred in CRC and other types of cancer, with a consistent copy number increase or decrease. To date, there is no report concerning the function of PDP1, C13orf27 and FHOD in cancer. Our results indicate the need to study these genes in rectal carcinogenesis. TRIB1 is a mammalian homolog of tribbles, an evolutionarily conserved Drosophila 
Table III. Genomic aberrations linked with clinicopathological characteristics of the rectal cases.

\begin{tabular}{|c|c|c|c|c|c|c|c|c|c|c|}
\hline \multirow[b]{2}{*}{ Cytoband } & \multirow[b]{2}{*}{ Change } & \multicolumn{3}{|c|}{$\mathrm{pN}$ status } & \multicolumn{3}{|c|}{ Distant metastasis } & \multicolumn{3}{|c|}{ Stage } \\
\hline & & Positive & Negative & P-value & Positive & Negative & P-value & Stage II & Stages III and IV & P-value \\
\hline \multirow[t]{2}{*}{ 4p16.1-p15.31 } & Loss & 9 & 2 & 0.036 & 4 & 7 & 0.430 & 1 & 10 & 0.013 \\
\hline & No loss & 17 & 20 & & 9 & 28 & & 19 & 18 & \\
\hline \multirow[t]{2}{*}{$4 q 34.3-q 35.1$} & Loss & 11 & 4 & 0.072 & 6 & 9 & 0.175 & 3 & 12 & 0.040 \\
\hline & No loss & 15 & 18 & & 7 & 26 & & 17 & 16 & \\
\hline \multirow[t]{2}{*}{ 7p12.3-p12.1 } & Gain & 12 & 1 & 0.001 & 4 & 9 & 0.726 & 1 & 12 & 0.004 \\
\hline & No gain & 14 & 21 & & 9 & 26 & & 19 & 16 & \\
\hline \multirow[t]{2}{*}{$8 p 21.1-p 12$} & Loss & 16 & 5 & 0.007 & 5 & 16 & 0.653 & 5 & 16 & 0.027 \\
\hline & No loss & 10 & 17 & & 8 & 19 & & 15 & 12 & \\
\hline \multirow[t]{2}{*}{$13 q 33.1-q 34$} & Gain & 13 & 3 & 0.008 & 3 & 13 & 0.358 & 3 & 13 & 0.023 \\
\hline & No gain & 13 & 19 & & 10 & 22 & & 17 & 15 & \\
\hline \multirow[t]{2}{*}{$17 q 24.2-q 25.3$} & Gain & 4 & 4 & 0.796 & 6 & 2 & 0.001 & 2 & 6 & 0.295 \\
\hline & No gain & 22 & 18 & & 7 & 33 & & 18 & 22 & \\
\hline
\end{tabular}

Table IV. Candidate target genes of gains and losses in rectal cancer.

\begin{tabular}{lll}
\hline Change & Cytoband & \multicolumn{1}{c}{ Genes (>5-fold change) } \\
\hline Gain & $8 \mathrm{q}$ & CA2, PDP1, ANGPT1, LOC346887, MAL2, NOV, TRIB1, ZNF572 \\
& $13 \mathrm{q}$ & OXGR1, PCDH9, EFNB2, C13orf27, LMO7, ARL11 \\
$17 \mathrm{q}$ & TTYH2, RAB37, MXRA7, SLC26A11, MGAT5B \\
& $20 \mathrm{p}$ & FOXA2, C20orf56, SLC24A3, CHGB, C20orf194, NRSN2 \\
& $20 \mathrm{q}$ & PMEPA1, PCK1, SULF2, LOC100240735, WFDC2, PHACTR3 \\
& $8 \mathrm{p}$ & Not found \\
Loss & $11 \mathrm{q}$ & Not found \\
& $18 \mathrm{q}$ & FHOD3, PSTPIP2, SMAD4, MBD2, BCL2, ST8SIA5 \\
\hline
\end{tabular}

Table V. Candidate targets in the Oncomine database.

\begin{tabular}{|c|c|c|c|c|}
\hline \multirow[b]{2}{*}{ Cytoband } & \multirow[b]{2}{*}{ Gene } & \multicolumn{2}{|c|}{ Colorectal cancer } & \multirow[b]{2}{*}{ Change in other cancers } \\
\hline & & $\mathrm{Up}$ & Down & \\
\hline \multirow[t]{3}{*}{$8 q$ gain } & PDP1 & 8 & 0 & $\begin{array}{l}\text { Cervical cancer, gastic cancer, head and neck cancer, kidney cancer, } \\
\text { leukemia, lymphoma, melanoma, pancreatic cancer }\end{array}$ \\
\hline & TRIB1 & 1 & 0 & $\begin{array}{l}\text { Brain and CNS cancer, breast cancer, esophageal cancer, } \\
\text { head and neck cancer, leukemia, lymphoma, melanoma, prostate cancer }\end{array}$ \\
\hline & ZNF572 & 2 & 0 & No \\
\hline \multirow[t]{2}{*}{ 13q gain } & OXGR1 & 4 & 1 & No \\
\hline & C13orf 27 & 5 & 0 & Cervical cancer \\
\hline $20 p$ gain & FOXA2 & 6 & 1 & Esophageal cancer \\
\hline \multirow[t]{2}{*}{ 20q gain } & PMEPA1 & 9 & 0 & $\begin{array}{l}\text { Bladder cancer, breast cancer, esophageal cancer, gastric cancer, } \\
\text { head and neck cancer, lung cancer, pancreatic cancer }\end{array}$ \\
\hline & PHACTR3 & 2 & 0 & Brain and CNS cancer, pancreatic cancer \\
\hline \multirow[t]{3}{*}{$18 \mathrm{q}$ loss } & FHOD3 & 0 & 1 & $\begin{array}{l}\text { Bladder cancer, brain and CNS cancer, breast cancer, } \\
\text { kidney cancer, prostate cancer }\end{array}$ \\
\hline & SMAD4 & 0 & 2 & Lymphoma \\
\hline & BCL2 & 0 & 14 & $\begin{array}{l}\text { Bladder cancer, brain and CNS cancer, breast cancer, head and neck cancer, } \\
\text { leukemia, lymphoma, ovarian cancer, prostate cancer, sarcoma }\end{array}$ \\
\hline
\end{tabular}




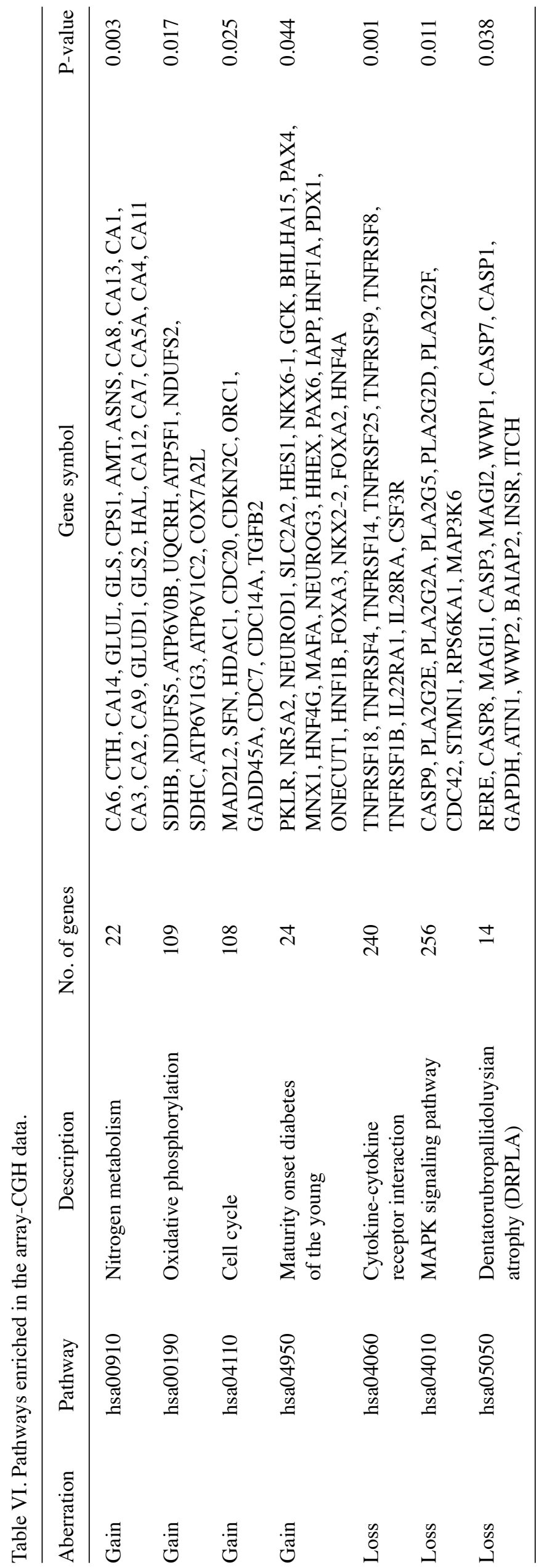

protein family that regulates protein degradation. In myeloid leukemogenesis, TRIB1 was found to be overexpressed and was a key mediator between the RTK-MAPK pathway and the C/ EBP transcription factor $(20,21)$. FOXA2 was found to function as a suppressor of tumor metastasis by inhibition of epithelialto-mesenchymal transition (EMT). Loss of FOXA2 expression due to epigenetic silencing was frequent in lung cancer $(22,23)$. PMEPA1 is a TGF- $\beta$ inducible gene and encodes an NEDD4 E3 ubiquitin ligase binding protein. PMEPA1 was found to be overexpressed in prostate, breast, renal cell, stomach and rectal carcinomas (24-26). PHACTR3 was identified as a PP1-binding protein and was selectively expressed in the brain. PHACTR3 was found to be overexpressed in $20 \%$ of non-small cell lung cancer (NSCLC), and was associated with reduced survival time of patients. In advanced neoplasia the methylation level of PHACTR3 was 70-fold higher than that in normal colon mucosa, and the sensitivity and specificity in stool assay were 55 and 95\%, respectively (27). Loss of SMAD4 expression was reported as a predictor of liver metastasis in CRC, and patients with reduced SMAD4 expression presented with a poor prognosis (28-30). Transgenic expression of SMAD4 was found to significantly reduce the oncogenic potential of SW620 and MC38 cell lines (31). Overall, these genes may be the target genes of genomic gains and losses in rectal cancer. Further research should be addressed to elucidate the roles of the candidate genes in rectal carcinogenesis.

In summary, the genomic aberrations identified in the present study can be suggested as candidate biomarkers with which to predict the clinical outcome of patients with rectal carcinoma and may be expected to serve to individualize the treatment of rectal cancer. Our study identified several candidate target genes of the most common gains and losses in rectal cancer, and our findings provide information to explore the role of these genes in the development and progression of rectal cancer.

\section{Acknowledgements}

This study was supported by the National Natural Science Foundation of China (30950013) and the Special Public Health Fund of China (200902002-5).

\section{References}

1. Ministry of Health, PCR. Chinese Health Statistical Digest, 2010. Available from: http://www.moh.gov.cn/publicfiles//business/ htmlfiles/zwgkzt/ptjty/digest2010/index.html.

2. Alazzouzi H, Alhopuro P, Salovaara R, Sammalkorpi H, Jarvinen H, Mecklin JP, Hemminki A, Schwartz S Jr, Aaltonen LA and Arango D: SMAD4 as a prognostic marker in colorectal cancer. Clin Cancer Res 11: 2606-2611, 2005.

3. Basseres DS, D'Alo F, Yeap BY, Lowenberg EC, Gonzalez DA, Yasuda H, Dayaram T, Kocher ON, Godleski JJ, Richards WG, Meyerson M, Kobayashi S, Tenen DG, Halmos B and Costa DB: Frequent downregulation of the transcription factor Foxa2 in lung cancer through epigenetic silencing. Lung Cancer 77: 31-37, 2012.

4. Bockmuhl U, Schmidt S, Petersen S and Petersen I: Deletion of chromosome $10 \mathrm{q}$ - a marker for metastasis of head-neck carcinomas? Laryngorhinootologie 79: 81-85, 2000 (In German).

5. Bosch LJ, Oort FA, Neerincx M, Khalid-de Bakker CA, Terhaar sive Droste JS, Melotte V, Jonkers DM, Masclee AA, Mongera S, Grooteclaes M, Louwagie J, van Criekinge W, Coupe VM, Mulder CJ, van Engeland M, Carvalho B and Meijer GA: DNA methylation of phosphatase and actin regulator 3 detects colorectal cancer in stool and complements FIT. Cancer Prev Res 5: 464-472, 2012. 
6. Dellas A, Torhorst J, Jiang F, Proffitt J, Schultheiss E, Holzgreve W, Sauter G, Mihatsch MJ and Moch H: Prognostic value of genomic alterations in invasive cervical squamous cell carcinoma of clinical stage IB detected by comparative genomic hybridization. Cancer Res 59: 3475-3479, 1999.

7. Diep CB, Kleivi K, Ribeiro FR, Teixeira MR, Lindgjaerde OC and Lothe RA: The order of genetic events associated with colorectal cancer progression inferred from meta-analysis of copy number changes. Genes Chromosomes Cancer 45: 31-41, 2006.

8. Fearon ER and Vogelstein B: A genetic model for colorectal tumorigenesis. Cell 61: 759-767, 1990.

9. Giannini G, Ambrosini MI, Di Marcotullio L, Cerignoli F,Zani M, MacKay AR, Screpanti I, Frati L and Gulino A: EGF- and cellcycle-regulated STAG1/PMEPA1/ERG1.2 belongs to a conserved gene family and is overexpressed and amplified in breast and ovarian cancer. Mol Carcinog 38: 188-200, 2003.

10. Hu N, Roth MJ, Emmert-Buck MR, Tang ZZ, Polymeropolous M, Wang QH, Goldstein AM, Han XY, Dawsey SM, Ding T, Giffen $\mathrm{C}$ and Taylor PR: Allelic loss in esophageal squamous cell carcinoma patients with and without family history of upper gastrointestinal tract cancer. Clin Cancer Res 5: 3476-3482, 1999.

11. Jemal A, Bray F, Center MM, Ferlay J, Ward E and Forman D: Global cancer statistics. CA Cancer J Clin 61: 69-90, 2011.

12. Jiang JK, Chen YJ, Lin CH, Yu IT and Lin JK: Genetic changes and clonality relationship between primary colorectal cancers and their pulmonary metastases - an analysis by comparative genomic hybridization. Genes Chromosomes Cancer 43: 25-36, 2005.

13. Jiang LX, Xu J, Wang ZW, Li DP, Peng ZH, Gao JJ, He L and Zheng HT: Tumor suppress genes screening analysis on $4 q$ in sporadic colorectal carcinoma. World J Gastroenterol 14 5606-5611, 2008.

14. Kawakami M, Yamaguchi T, Takahashi K, Matsumoto $H$ Yasutome M, Horiguchi S, Hayashi Y, Funata N and Mori T: Assessment of SMAD4, p53, and Ki-67 alterations as a predictor of liver metastasis in human colorectal cancer. Surg Today 40: 245-250, 2010

15. Kimura Y, Noguchi T, Kawahara K, Kashima K, Daa T and Yokoyama S: Genetic alterations in 102 primary gastric cancers by comparative genomic hybridization: gain of $20 \mathrm{q}$ and loss of $18 \mathrm{q}$ are associated with tumor progression. Mod Pathol 17: 1328-1337, 2004.

16. Knosel T, Schluns K, Dietel M and Petersen I: Chromosomal alterations in lung metastases of colorectal carcinomas: associations with tissue specific tumor dissemination. Clin Exp Metastasis 22: 533-538, 2005.

17. Lagerstedt KK, Staaf J, Jonsson G, Hansson E, Lonnroth C, Kressner U, Lindstrom L, Nordgren S, Borg A and Lundholm K Tumor genome wide DNA alterations assessed by array CGH in patients with poor and excellent survival following operation for colorectal cancer. Cancer Inform 3: 341-355, 2007.
18. Lei T, Chen WQ, Zhang SW, Lei TH, Ying Q, He ZY and Wang XH: Prevalence trend of colorectal cancer in 10 cities and counties in China from 1988 to 2002. Zhonghua Zhong Liu Za Zhi 31: 428-433, 2009 (In Chinese).

19. Lengauer C, Kinzler KW and Vogelstein B: Genetic instability in colorectal cancers. Nature 386: 623-627, 1997.

20. Lengauer C, Kinzler KW and Vogelstein B: Genetic instabilities in human cancers. Nature 396: 643-649, 1998.

21. Li HL, Gao YT, Zheng Y, Zhang W, Gao LF, Xu B and Xiang YB: Incidence trends of colorectal cancer in urban Shanghai, 1973-2005. Zhonghua Yu Fang Yi Xue Za Zhi 43: 875-879, 2009 (In Chinese).

22. Losi L, Bouzourene H and Benhattar J: Loss of Smad4 expression predicts liver metastasis in human colorectal cancer. Oncol Rep 17: 1095-1099, 2007.

23. Nakao M, Kawauchi S, Furuya T, Uchiyama T, Adachi J, Okada T, Ikemoto K, Oga A and Sasaki K: Identification of DNA copy number aberrations associated with metastases of colorecta cancer using array CGH profiles. Cancer Genet Cytogenet 188 70-76, 2009.

24. Nakao M, Kawauchi S, Uchiyama T, Adachi J, Ito H, Chochi Y, Furuya T, Oga A and Sasaki K: DNA copy number aberrations associated with the clinicopathological features of colorectal cancers: Identification of genomic biomarkers by array-based comparative genomic hybridization. Oncol Rep 25: 1603-1611, 2011.

25. Petersen S, Aninat-Meyer M, Schluns K, Gellert K, Dietel M and Petersen I: Chromosomal alterations in the clonal evolution to the metastatic stage of squamous cell carcinomas of the lung. $\mathrm{Br}$ J Cancer 82: 65-73, 2000.

26. Rae FK, Hooper JD, Nicol DL and Clements JA: Characterization of a novel gene, STAG1/PMEPA1, upregulated in renal cell carcinoma and other solid tumors. Mol Carcinog 32: 44-53, 2001.

27. Rothlisberger B, Heizmann M, Bargetzi MJ and Huber AR TRIB1 overexpression in acute myeloid leukemia. Cancer Genet Cytogenet 176: 58-60, 2007.

28. Tang Y, Shu G, Yuan X, Jing N and Song J: FOXA2 functions as a suppressor of tumor metastasis by inhibition of epithelialto-mesenchymal transition in human lung cancers. Cell Res 21 : 316-326, 2011.

29. Xu LL, Shanmugam N, Segawa T, Sesterhenn IA, McLeod DG, Moul JW and Srivastava S: A novel androgen-regulated gene, PMEPA1, located on chromosome 20q13 exhibits high level expression in prostate. Genomics 66: 257-263, 2000.

30. Yokoyama T, Kanno Y, Yamazaki Y, Takahara T, Miyata S and Nakamura T: Trib1 links the MEK1/ERK pathway in myeloid leukemogenesis. Blood 116: 2768-2775, 2010.

31. Zhang B, Halder SK, Kashikar ND, Cho YJ, Datta A, Gorden DL and Datta PK: Antimetastatic role of Smad4 signaling in colorectal cancer. Gastroenterology 138: 969-980, 2010. 